\title{
FREQUENCIAS DOS TIPOS SANGUÍNEOS E TÍTULOS DOS ALOANTICORPOS EM FELINOS DOMÉSTICOS
}

\section{FREQUENCY OF BLOOD GROUPS AND TITERS OF ALLOANTIBODIES IN DOMESTIC CATS}

\author{
Anderson Barros Teixeira Pinto ${ }^{1^{*}}$ \\ Miguel Ângelo da Silva Medeiros² \\ Mariana Palha de Brito Jardim ${ }^{1}$ \\ Antonio Peixoto Albernaz ${ }^{1}$ \\ ${ }^{1}$ Universidade Estadual do Norte Fluminense Darcy Ribeiro, Campos dos Goytacazes, RJ, Brasil. \\ 'Universidade Federal Fluminense, Niterói, RJ, Brasil, e Universidade Castelo Branco, Rio de Janeiro, RJ, \\ Brasil. \\ *Autor para correspondência - andersonbtvet@gmail.com
}

\begin{abstract}
Resumo
A área da hemoterapia necessita de testes de compatibilidade sanguínea confiáveis, como a tipagem sanguínea, para se evitarem possíveis reações transfusionais, mas em felinos é também importante para se evitar a isoeritrólise neonatal. Transfusões sanguíneas realizadas entre felinos doadores e receptores que não possuem compatibilidade sanguínea podem refletir em reação transfusional aguda, particularmente severa quando o sangue tipo A é transfundido em um gato tipo B, pois geralmente este último possui altos níveis de aloanticorpos de ocorrência natural. Portanto, o conhecimento da frequência dos tipos sanguíneos da população de gatos de uma região pode auxiliar na determinação dos riscos de reações transfusionais e de ocorrência de isoeritrólise neonatal. Tais riscos podem ser prevenidos com a tipagem sanguínea em casos de transfusão. Foram coletadas 100 amostras sanguíneas de felinos para a realização da tipagem sanguínea com plasmas reagentes anti-A e anti-B conhecidas e titulações de aloanticorpos anti-A e anti-B dos plasmas armazenados. A distribuição das frequências dos grupos sanguíneos foi 96\% de felinos com tipo sanguíneo A e 4\% de felinos com tipo sanguíneo $\mathrm{B}$, não sendo encontrado na amostra populacional de felino tipo AB. Há um grande risco de reação adversa através da transfusão sanguínea randomizada entre felinos não tipados previamente.

Palavras-chave: gatos; imunohematologia; medicina transfusional; tipagem sanguínea.
\end{abstract}

\begin{abstract}
Hemotherapy requires reliable blood compatibility tests, such as blood typing, to avoid possible transfusion reactions in cats. However, it is also important to avoid neonatal isoerythrolysis. When blood transfusions are performed between incompatible feline donors and recipients, they may develop acute transfusion reactions, especially severe when type A blood is transfused into a type $B$ cat because it has high levels of anti-A alloantibodies. Therefore, knowing on the blood type frequency in feline population of some region can help to determine the transfusion reaction risks and the occurrence of neonatal isoerythrolysis. Addicionally, such risks may be prevented through blood typing, in cases of transfusion. One hundred feline blood samples were collected and anti-A and anti-B blood reagent typing tests were performed, plus titration of alloantibodies of stored plasma. These tests showed a $96 \%$ frequency of type A blood and only $4 \%$ of type B blood among tested cats. We did not find any AB type blood cat. There is a great risk of adverse reactions after random blood transfusions between non-typed cats.
\end{abstract}


Keywords: blood typing; cats; immunohematology; transfusion medicine.

Enviado em: 04 de março 2011

Aceito em: 21 de março 2016

\section{Introdução}

A tipagem sanguínea possui uma grande importância na área da hemoterapia em qualquer espécie animal para se evitar possíveis reações transfusionais, mas em felinos é também importante para se evitar a isoeritrólise neonatal (doença hemolítica do recém nascido). As transfusões sanguíneas realizadas entre gatos doadores e receptores que não possuem compatibilidade sanguínea podem provocar uma reação transfusional aguda, particularmente severa quando o sangue tipo A é transfundido em um gato tipo $\mathrm{B}$, pois geralmente este último possui altos níveis de aloanticorpos de ocorrência natural. Nestes casos, poucos mililitros de sangue são suficientes para causar uma reação que pode ser eventualmente fatal ${ }^{(1)}$. Atualmente, o uso de transfusão sanguínea tem aumentado na medicina felina ${ }^{(2,3)}$.

Nos gatos domésticos é conhecido apenas um único sistema de grupos sanguíneos $\mathrm{AB}$ composto por três tipos sanguíneos: tipo $\mathrm{A}, \mathrm{B}$ e o raro tipo $\mathrm{AB}^{(4,5)}$. Grande número de antígenos proteicos e carboidratos complexos estão presentes na superfície externa dos eritrócitos, e o rearranjo destas moléculas formam os antígenos de membrana nestas células. Foram caracterizados bioquimicamente os epítopos de carboidratos fundamentando o sistema $\mathrm{AB}$ com os ácidos siálicos, ácido $\mathrm{N}$-glicolineurâmico e ácido $\mathrm{N}$-acetilneurâmico, correspondendo aos oligossacarídeos e antígenos A e B, respectivamente, em uma ceramida dihexosídeo ${ }^{(6,7)}$.

Tipos sanguíneos felinos e tipos sanguíneos incompatíveis, incluindo diferenças geográficas, modos de herança, severidade de reações transfusionais e incidência de isoeritrólise neonatal, têm sido estudados amplamente durante as últimas duas décadas ${ }^{(4,5,8)}$. A determinação das frequências do tipo A, B e AB em populações de gatos com raça definida pode auxiliar na avaliação do risco de reações transfusionais através de transfusões incompatíveis e o risco de a ninhada nascer com isoeritrólise neonatal, quando são descendentes de pais de tipos sanguíneos desconhecidos ${ }^{(9)}$.

Os tipos sanguíneos A e B são herdados como características Mendelianas transmitidas por genes que codificam os tipos sanguíneos A e/ou B presentes no mesmo locus. O tipo A é dominante em relação ao tipo $\mathrm{B}^{(6,8)}$. Os felinos tipo $\mathrm{A}$ podem ser heterozigotos ou homozigotos. Gatos tipo $\mathrm{B}$ são homozigotos. $\mathrm{O}$ terceiro alelo, $\mathrm{AB}$, que é recessivo para o alelo $\mathrm{A}$, mas é dominante em relação ao alelo $\mathrm{B}$, determina a herança do tipo $\mathrm{AB}$. A presença de antígenos $\mathrm{A}$ e $\mathrm{B}$ em fetos felinos pode ser descoberta em 38 dias de gestação ${ }^{(2)}$.

$\mathrm{A}$ frequência de tipos $\mathrm{A}, \mathrm{B}$ e $\mathrm{AB}$ varia geograficamente e entre $\operatorname{raças}^{(8)}$. O tipo $\mathrm{A}$ é o tipo sanguíneo predominante mundialmente, embora a prevalência do tipo $\mathrm{A}, \mathrm{B}$ e AB dentro da população felina varie entre gatos de sangue puro (raça específica) e gatos domésticos ${ }^{(8,10-12)}$. De acordo com Giger $^{(13)}$, as percentagens dos tipos sanguíneos em algumas raças selecionadas demonstram que há predisposição genética de certos tipos sanguíneos em raças específicas.

Embora gatos tipo B sejam raros em populações criadas randomizadamente, misturas de raças estão aumentando a frequência de gatos tipo B. Por exemplo, gatos tipo B são mais comuns em populações na Califórnia e Austrália do que na Europa e no resto dos Estados Unidos ${ }^{(6,8)}$.

A distribuição dos tipos sanguíneos varia de acordo com a região geográfica e entre as diferentes raças de felinos, mas pouco se sabe sobre os felinos do Brasil. No Brasil, poucos animais de raças puras foram estudados. Em um estudo feito por Guerra e colaboradores ${ }^{(14)}$, foram tipados 17 gatos siameses e um Oriental, sendo 100\% deles do tipo A. Entretanto, o mesmo não pôde ser aplicado para as raças Himalaya e Persa tipados, pois foram encontrados os tipos A e B, mostrando a importância do conhecimento prévio do tipo sanguíneo destes indivíduos antes de transfusões ou seleção de reprodutores. No trabalho mais recente realizado na cidade do Rio de Janeiro por Medeiros e colaboradores $^{(15)}, 94,8 \%$ dos gatos tipados foram classificados como grupo sanguíneo A. Neste mesmo trabalho, a frequência de felinos com tipo sanguíneo B foi de $2,9 \%$ e felinos com tipo sanguíneo AB foi de $2,3 \%{ }^{(15)}$. 
Embora os antígenos de superfície dos eritrócitos no sistema de grupo sanguíneo AB felino sejam diferentes daqueles do sistema de grupo sanguíneo humano ABO, os gatos também possuem aloanticorpos de ocorrência natural (também conhecidos como isoanticorpos) contra o antígeno do grupo sanguíneo ausente ${ }^{(16,17)}$. Felizmente, os anticorpos de ocorrência natural de significado clínico raramente ocorrem nos animais e, consequentemente, a reação transfusional contra os eritrócitos incompatíveis geralmente não ocorre no momento da primeira transfusão sanguínea. No entanto, exceções ocorrem na espécie felina (como no caso do sistema de grupo sanguíneo AB em gatos), em que gatos positivos tipo B têm anticorpos de ocorrência natural anti-A com altos títulos hemolíticos. Estes anticorpos são de grande importância na prática clínica porque eles podem provocar reações de incompatibilidade sanguínea em gatos ${ }^{(16)}$.

Apesar de numerosos relatos documentados sobre as variações geográficas e entre as raças na prevalência dos tipos sanguíneos felinos ${ }^{(18)}$, a distribuição de títulos de anticorpos de ocorrência natural tem sido pouco investigada no Brasil ${ }^{(19)}$. De acordo com Arikan e Akkan ${ }^{(16)}$ e Knottenbelt e colaboradores $^{(20)}$, os títulos de anticorpos não variam entre os sexos dos gatos.

Em relatos anteriores, títulos de isoaglutininas anti-A moderados a altos foram encontrados em soros de gatos tipo B (geralmente $>32$ ) ambos hemoaglutininas (principalmente IgM) e hemolisinas (com formação de fixação de complemento; ambos IgM e IgG). Um terço ou menos dos gatos tipo A possuem anticorpos circulantes contra células tipo B, geralmente com apenas poucos títulos $(<8)$. No entanto, os gatos tipo $\mathrm{AB}$ não possuem isoaglutininas ${ }^{(4)}$.

Em felinos domésticos, as transfusões sanguíneas são realizadas por várias razões, mas o emprego da transfusão é, na sua maior parte, por causa de anemia hemorrágica, anemia hemolítica e anemia devido à insuficiência medular. Outra indicação ocasional inclui metahemoglobinemia severa, pela intoxicação por paracetamol ${ }^{(21)}$. A transfusão em anemias por insuficiência medular é mais comum em gatos do que em cães, possivelmente por ser um tipo de anemia mais frequente, sendo mais comum no felino devido à insuficiência renal crônica e infecções retroviróticas ${ }^{(2,22)}$. A anemia representa um desafio em termos de estabelecimento e suporte ao paciente. Administração apropriada da transfusão permite ao clínico mais tempo para investigar, diagnosticar e tratar a causa subjacente ${ }^{(21)}$.

A importância deste estudo se deve à precariedade de informações nas regiões do país, principalmente entre raças puras de felinos ${ }^{(19)}$, sendo uma pesquisa de suma importância na clínica médica veterinária devido ao crescente número de felinos portadores do tipo sanguíneo $\mathrm{B}$, sendo necessária, portanto, a diferenciação de indivíduos tipo sanguíneo $\mathrm{A}$, do tipo sanguíneo $\mathrm{B}$ e do $\mathrm{AB}$ para que possa ser realizado um tratamento hemoterápico.

\section{Material e Métodos}

A pesquisa foi submetida à comissão de Ética de Uso de Animais (CEUA) da Universidade Estadual do Norte Fluminense Darcy Ribeiro e aprovada sob protocolo $n^{\circ} 92$. Foram coletadas amostras sanguíneas de 100 gatos independentes de raça, sexo e idade em Campos dos Goytacazes, RJ. Os animais foram selecionados de atendimentos clínicos no Hospital Veterinário da Universidade Estadual do Norte Fluminense (UENF), de animais mantidos em gatis em diferentes locais da cidade e também de atendimentos pessoais. As coletas foram realizadas por venopunção cefálica e as amostras sanguíneas $(1,0-2,0 \mathrm{~mL})$ armazenadas em tubos contendo EDTA $\mathrm{K}_{3}$. As amostras sanguíneas foram transportadas em frasco (Vacuette ${ }^{\circledR}$ ) e armazenadas a $4{ }^{\circ} \mathrm{C}$ até que a tipagem sanguínea fosse executada. Foram realizadas as lavagens de hemácias adicionando-se $3 \mathrm{~mL}$ de tampão salino fosfato (PBS) à $0,9 \%$ com pH de 7.2 em cada tubo Falcon para obtenção da suspensão de hemácias a 5\%. Os plasmas que serviram como reagentes anti-A e anti-B foram previamente titulados para demonstrar que são capazes de promoverem hemaglutinação.

Foram utilizados dois tubos para realização da tipagem sanguínea, sendo estes para cada amostra sanguínea. Um tubo continha um plasma anti-B de um gato tipo A conhecido e outro tubo continha plasma anti-A de um gato tipo B conhecido. No tubo definido anti-B havia $25 \mu \mathrm{L}$ de plasma anti-B capaz de aglutinar hemácias com antígeno B e no tubo definido como anti-A havia $25 \mu \mathrm{L}$ de plasma anti-A capaz de aglutinar hemácias com antígeno A. Em cada um dos dois tubos foram adicionados 
$25 \mu \mathrm{L}$ de suspensão de hemácias a 5\% de um felino para realização da tipagem sanguínea. Após o preparo da solução dos plasmas reagentes com a suspensão de hemácias de cada felino os tubos foram colocados no banho-maria à $37^{\circ} \mathrm{C}$ por 30 minutos, para evidenciar algum padrão de aglutinação. Após a realização da tipagem sanguínea, todos os plasmas dos felinos avaliados, com os grupos sanguíneos identificados, foram separados e armazenados à $-20^{\circ} \mathrm{C}$ para posterior realização dos testes de contra-tipagem e titulação dos aloanticorpos.

A contra-tipagem foi considerada um teste de confirmação e executada em cada amostra descrevendo os três tubos como A, B e controle. $25 \mu \mathrm{L}$ de suspensão de hemácias a $5 \%$ de conhecido tipo A e B foram acrescentados ao tubos 1 e 2 , respectivamente. $25 \mu \mathrm{L}$ de soro não diluído de cada gato foram adicionados e misturados suavemente nos dois tubos. O controle foi obtido misturando-se os próprios eritrócitos do gato e seu soro, sendo assim o controle negativo. Foram observados resultados de hemaglutinação depois de 30 minutos de incubação a $37^{\circ} \mathrm{C}$, para confirmação das tipagens sanguíneas. Outro teste de confirmação foi a prova da lectina. Os testes de aglutinação com a utilização da solução de lectina foram executados em algumas amostras sanguíneas tipo A, selecionadas ao acaso, e todas as amostras sanguíneas tipo B em tubos atendendo as condições usadas pelos protocolos comerciais. Todas as alíquotas escolhidas com sangue total $(25 \mu \mathrm{L})$ foram colocadas em tubos de vidro e misturadas com um volume da mesma proporção de solução de lectina Triticum vulgaris $(100 \mathrm{ug} / \mathrm{mL})$ em tampão salino de fosfato (PBS), pH 7.2. Depois da incubação em banho-maria a $37^{\circ} \mathrm{C}$ durante 30 minutos, os tubos foram centrifugados a $1000 \mathrm{~g}$ força por 30 segundos e a aglutinação de eritrócitos foi registrada como positiva (tipo $\mathrm{B}$ ou $\mathrm{AB}$ ) ou negativa (tipo $\mathrm{A}$ ) por inspeção visual após se misturar suavemente a solução nos tubos.

A titulação foi realizada em microplaca de 96 poços e foram utilizados os plasmas armazenados de conhecidos anti-B e anti-A e suspensões de hemácias a 5\% de conhecidos sangues tipo A e tipo B. Seguiu-se o protocolo realizado por Knottenbelt e colaboradores ${ }^{(17)}$ e realizou-se a titulação por técnicas manuais de aglutinação direta quantitativa dos plasmas anti-A e anti-B armazenados ${ }^{(17)}$. Primeiramente, foram adicionados na primeira coluna $50 \mu \mathrm{L}$ de plasmas anti-A ou anti-B dos gatos nas fileiras correspondentes a cada amostra de plasma (fileira A a H). A partir da segunda coluna até a décima segunda coluna foram adicionados em todas as fileiras $25 \mu \mathrm{L}$ de tampão salino fosfato (PBS) a 0,9\% com pH 7.2. Desta forma, foram diluídos os plasmas, inicialmente retirando-se 25 $\mu \mathrm{L}$ dos plasmas e transferindo para o poço seguinte à direita e, assim, repetindo o procedimento transferindo $25 \mu \mathrm{L}$ para os poços seguintes, para formar as diluições dos plasmas ao PBS de 1:2 a 1:2048. Posteriormente, foi adicionada a cada fileira a suspensão de hemácias de determinado tipo sanguíneo, como suspensão de hemácias de um felino tipo B sendo adicionado em plasmas que continham anti-B e suspensão de hemácias a 5\% de um felino tipo A sendo adicionado em plasmas anti-A.

Os dados foram tabelados e foi realizada estatística descritiva a fim de se obter principalmente a frequência dos tipos sanguíneos em percentuais, identificando dentro da amostra populacional a proporção existente entre os tipos sanguíneos. Também foi realizada a análise descritiva quantitativa e qualitativa dos dados de tipagem sanguínea, das provas de confirmação e das titulações de aloanticorpos dos plasmas armazenados.

Os cálculos estatísticos foram baseados nas leis de probabilidade de eventos independentes que usam a fórmula $\mathrm{P}(\mathrm{A} \cap \mathrm{B})=\mathrm{P}(\mathrm{A}) . \mathrm{P}(\mathrm{B})$ para determinar a probabilidade ou risco de ocorrer reação transfusional, na escolha aleatória do doador e receptor de sangue, baseado na determinação da frequência de tipos sanguíneos.

Os dados obtidos de titulação foram tabulados em Excel (Microsoft Office 2007) para delineamento e separação dos grupos de números de animais em 2 variáveis, faixas etárias e títulos de aloanticorpos anti-B na diluição de 1:2, 1:4 e 1:8. As faixas etárias foram dividas em três grupos: felinos jovens (idade inferior ou igual a 2 anos); adultos (idade superior à 2 anos e inferior ou igual a 6 anos de idade); idoso (idade superior a 6 anos). Posteriormente, foi realizado o teste não paramétrico Qui-quadrado de Pearson por independência $(\mathrm{p} \leq 0,05)$ para avaliar se os valores das titulações são independentes das faixas etárias citadas, desta forma, verificando se há alguma relação entre os títulos e às idades dos animais. 


\section{Resultados e Discussão}

A tipagem sanguínea em felinos domésticos é de suma importância na prática clínica para prevenir reações hemolíticas transfusionais agudas, isoeritrólise neonatal e sensibilização por incompatibilidade sanguínea. A tipagem sanguínea tem sido realizada em raças domésticas mestiças e puras pelo mundo inteiro mas não em países da América do Sul. No Rio de Janeiro, a conduta para realização das transfusões sanguíneas tem sido baseada somente em testes de compatibilidade sanguínea ${ }^{(15)}$. Todavia, os testes de compatibilidade do doador e do receptor não previne completamente o risco de transfundir sangues incompatíveis pois alguns animais necessitam de títulos significantes de aloanticorpos de ocorrência natural ${ }^{(3)}$.

No presente estudo a distribuição da frequência total na amostra populacional ficou em $96 \%$ dos felinos sendo do tipo sanguíneo A e 4\% dos felinos sendo do tipo sanguíneo B, não havendo nenhuma frequência para o tipo sanguíneo $\mathrm{AB}$, por não ter sido encontrado felino pertecente a este grupo. Em relação às raças indeterminadas ou mestiças, tanto felinos de pêlo curto quanto pêlo longo, a distribuição da frequência na cidade foi de $98,8 \%$ em felinos com tipo sanguíneo A e 1,2\% em felinos do tipo sanguíneo $B$, não havendo frequência em felinos com o tipo sanguíne $A B$. Estes dados são compatíveis com estudos prévios principalmente em relação à frequência do tipo sanguíneo $\mathrm{A}$ em gatos mestiços, que em outros países encontra-se elevada, apresentando frequências superiores a $90 \%$ neste grupo sanguíneo ${ }^{(1,8,12,17,19,23-28)}$. A Tabela 1 apresenta os resultados das frequências dos tipos sanguíneos dos felinos domésticos.

Tabela 1: Frequência dos tipos sanguíneos dos felinos domésticos após a identificação dos antígenos eritrocitários

\begin{tabular}{lccc}
\hline & \multicolumn{2}{c}{ Frequência dos grupos sanguíneos dos felinos domésticos } \\
\cline { 2 - 4 } Raça & Tipo sanguíneo A & Tipo sanguíneo B & Tipo sanguíneo AB \\
\hline Indeterminada & $98,8 \%(\mathrm{n}=85)$ & $1,2 \%(\mathrm{n}=1)$ & $0 \%(\mathrm{n}=0)$ \\
Siamês & $100 \%(\mathrm{n}=7)$ & $0 \%(\mathrm{n}=0)$ & $0 \%(\mathrm{n}=0)$ \\
Persa & $57,1 \%(\mathrm{n}=4)$ & $42,9 \%(\mathrm{n}=3)$ & $0 \%(\mathrm{n}=0)$ \\
\hline
\end{tabular}

Em felinos mestiços a frequência de animais pertencentes ao grupo sanguíneo B foi relativamente baixa, pois encontrar felinos com este tipo sanguíneo é raro, o que é consistente com o que tem sido observado nestes felinos em outras regiões do mundo ${ }^{(12,15)}$.

Não foi encontrado felino doméstico do grupo sanguíneo $A B$ dentro da distribuição de felinos mestiços ou de raça indeterminada; portanto, a frequência para este tipo sanguíneo foi $0 \%$. Outros trabalhos também não evidenciaram, na população de felinos, animais com este tipo sanguíneo. No Brasil, na cidade de Porto Alegre do estado do Rio Grande do Sul, Lacerda e colaboradores ${ }^{(19)}$ também não encontraram este tipo sanguíneo em felinos mestiços. Também não foram relatados felinos com este tipo sanguíneo na Alemanha, Áustria, Dinamarca, Escócia, Finlândia, França, Holanda, Hungria, Itália, Suíça e Japão ${ }^{(1,12,23-25,27,29)}$.

Em relação às raças puras específicas avaliadas, foram estudadas duas raças específicas, a raça Persa e a raça Siamês. Dentre os gatos persas, foi encontrado neste trabalho uma frequência de $57,1 \%$ de animais com tipo sanguíneo A e 42,9\% com tipo sanguíneo B. Estes valores se aproximam muito do trabalho realizado, na Austrália, por Malik e colaboradores ${ }^{(6)}$, que verificaram uma distribuição da frequência do tipo sanguíneo A e B de $67 \%$ e $22 \%$, respectivamente. No entanto, outros trabalhos relataram frequências maiores do tipo sanguíneo A, que variaram de valores superiores de $80 \%$ a $100 \%(8,12,14,17,30)$.

A frequência de felinos na raça Persa com tipo sanguíneo B encontrada no presente trabalho não é semelhante à encontrada em outros relatos na literatura, pois este possui valor superior. No entanto, sabe-se que a discrepância existente do tipo sanguíneo B pode ser devida ao baixo número de felinos desta raça estudados ${ }^{(12)}$. As diferenças entre as frequências de felinos com tipo sanguíneo B se deve ao fato de que há variações geográficas marcantes na prevalência do tipo sanguíneo B em gatos Persas, 
como verificado em vários estudos realizados nesta raça na Europa ${ }^{(8,20,29,31)}$; portanto, estes achados suportam a teoria de que a prevalência dos tipos sanguíneos pode apresentar variações geográficas marcantes em raças específicas ${ }^{(17)}$.

Não foi encontrado nenhum tipo sanguíneo $\mathrm{AB}$ entre os gatos persas semelhantes a muitos outros trabalhos ${ }^{(1,8,12,14,17)}$. Entretanto, altas frequências neste tipo sanguíneo foram encontradas em alguns trabalhos realizados no Japão, Portugal e Sidney, com frequências de 18,2\%, 14,3\% e 11\%, respectivamente ${ }^{(6,30,32)}$. Essas frequências possivelmente estão presentes e aumentadas devido aos cruzamentos de felinos da mesma raça que possuem prevalência neste tipo sanguíneo $\mathrm{AB}$ ou refletem no desvio genético randomizado que resulta em um aumento na frequência do alelo $\mathrm{AB}^{(17,30)}$.

Um dos principais testes de confirmação realizados neste trabalho foi o teste de contra-tipagem realizado em todos os plasmas armazenados de todos os animais. Amostras de plasmas de todos os felinos foram usadas para ensaios de aglutinações como descrito por Giger e colaboradores ${ }^{(33)}$ e Bucheler e Giger ${ }^{(34)}$. Portanto, foi realizada a contra-tipagem de 96 plasmas de felinos com tipo sanguíneo A e quatro plasmas de felinos do tipo sanguíneo B. Neste estudo, de todos os 96 plasmas dos felinos com tipo sanguíneo $\mathrm{A}$, apenas um $(1,04 \%)$ não foi capaz de promover aglutinação às hemácias de um sangue tipo B conhecido, quando visualizado ao nível microscópico, em contraste com trabalho realizado nos Estados Unidos por Bucheler e Giger ${ }^{(34)}$, que relataram que todos os plasmas de felinos tipo A aglutinaram hemácias tipo B quando visualizadas ao nível microscópico. No entanto, um trabalho realizado por Arikan e Akkan ${ }^{(16)}$ relatou que seis plasmas dos felinos tipo A (20\%) de 33 não foram capazes de promover aglutinação em hemácias tipo B quando visualizado a nível microscópico. Knottenbelt e colaboradores ${ }^{(20)}$ relataram que 17 plasmas $(27,9 \%)$ de felinos tipo A de 61 não foram capazes de promover a aglutinação a hemácias tipo B. Contudo, os trabalhos relataram que a maioria dos plasmas de felinos tipo A foram capazes de promover aglutinação a hemácias de um sangue tipo $\mathrm{B}^{(16,20)}$.

Na contra-tipagem, os quatro plasmas dos felinos identificados como tipo sanguíneo B também foram colocados à prova com hemácias de um sangue tipo A conhecido e todos foram capazes de promover aglutinações até mesmo significativas ao nível macroscópico, sendo assim fortes aglutinações. O achado em que todos os gatos tipo B possuem anticorpos anti-A hemaglutinantes está de acordo com estudos prévios ${ }^{(4,16,20,33,34)}$.

$\mathrm{O}$ resultado do presente estudo indica que a transfusão de sangue de receptores com tipo sanguíneo A para um felino tipo B tem um potencial de resultar em uma reação transfusional de 3,84\% em uma transfusão randomizada. Este resultado de probabilidade é semelhante ao encontrado por Medeiros e colaboradores ${ }^{(15)}$, que encontraram uma probabilidade de um tipo A receber um sangue tipo B em uma primeira transfusão randomizada de $2,25 \%$ e de receber um tipo $\mathrm{AB}$ de $2,20 \%$.

Foram testadas as amostras de plasmas de 96 animais com tipo sanguíneo A para titulação de aloanticorpos anti-B. Destes, 30 amostras apresentaram aglutinações na diluição 1:2 (31,25\%), sendo assim título 2. Foram encontrados resultados semelhantes em estudos no Reino Unido e Turquia ${ }^{(16,20,35)}$. No entanto, 16 amostras apresentaram apenas fracas aglutinações na diluição 1:2 (16,67\%), somente em visualizações microscópicas, representada por "M", semelhantes aos encontrados por Arikan e Akkan $^{(16)}$ e Gurkan e colaboradores ${ }^{(35)}$ em felinos tipo A na Turquia.

A proporção de plasmas dos felinos tipo A contendo título 4 foi a maior, sendo de $39,58 \%$, semelhante aos trabalhos realizados por Arikan e Akkan ${ }^{(16)}$ e Gurkan e colaboradores ${ }^{(35)}$, que encontraram uma proporção de $27,27 \%$ e 34,4\%, respectivamente, de plasmas com título 4; contudo, Knottenbelt e colaboradeores $^{(20)}$ encontraram uma proporção menor que os plasmas com título 2 , no caso uma proporção de $11,47 \%$. Foi encontrada uma proporção de $11,46 \%$ com título 8 , porém em trabalhos realizados por Knottenbelt e colaboradores ${ }^{(20)}$, Arikan e Akkan ${ }^{(16)}$ e Gurkan e colaboradores ${ }^{(35)}$ verificouse proporção menor de amostras com título 8 comparados com o atual trabalho, compreendidos em $3,19 \%, 6,06 \%$ e $4,0 \%$, respectivamente. Apenas um plasma de um felino tipo A $(1,04 \%)$ no presente trabalho não foi capaz de promover aglutinação (título 0), como foi descrita nos resultados de contra-tipagem, estando de acordo com trabalhos prévios ${ }^{(16,20,35)}$. A distribuição das titulações dos aloanticorpos anti-B na microplaca de 96 poços está representada na Figura 1 e na Figura 2. 


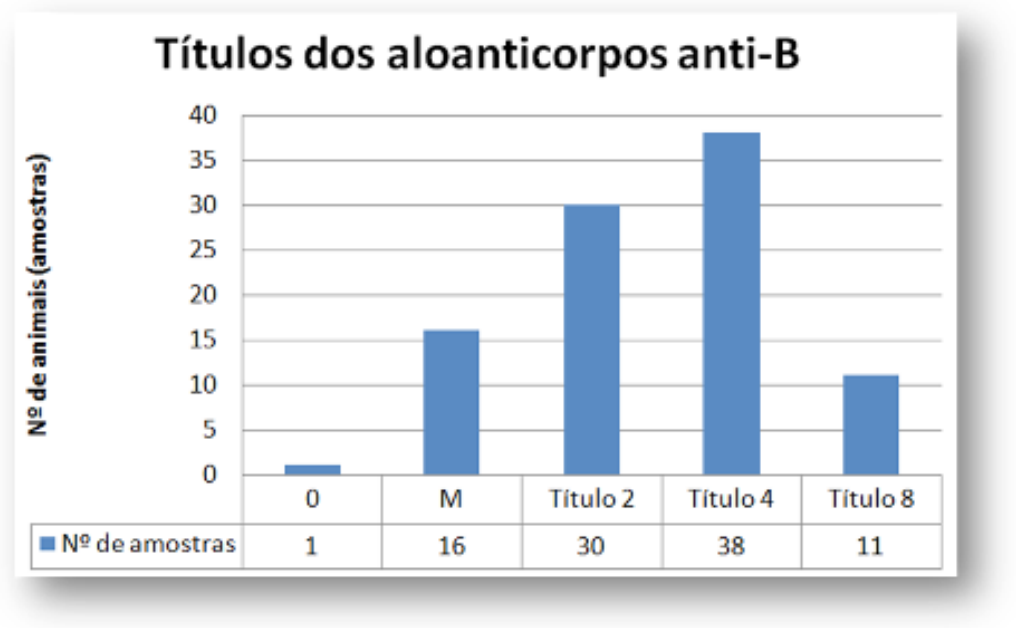

Figura 1: Gráfico representando o número de amostras de plasmas para cada título de aloanticorpos anti-B.

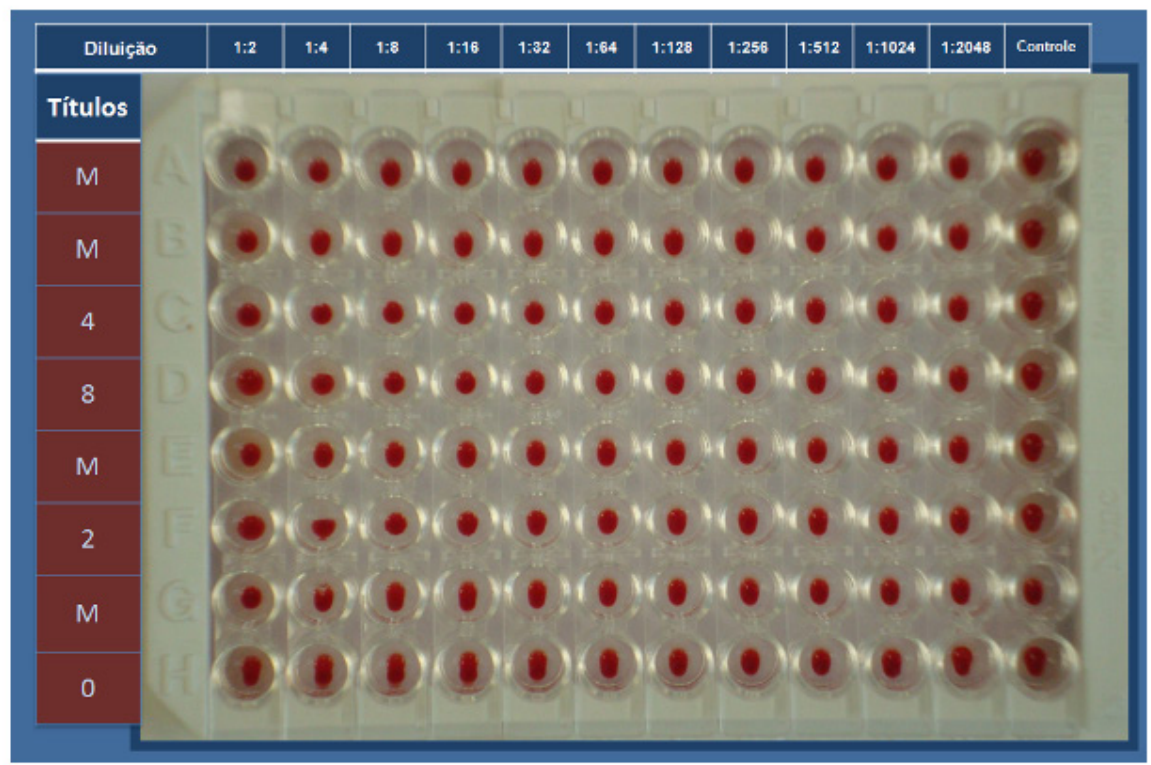

Figura 2: Titulação em diluições em PBS realizada em microplaca de 96 poços de plasmas com aloanticorpos anti-B, todas as titulações conferidas em microscopia óptica. Os títulos para cada plasma se encontram na barra ao lado da foto.

A titulação de aloanticorpos anti-A foi obtida dos plasmas dos quatro gatos tipo B. Todos os gatos tipo $\mathrm{B}$ evidenciaram fortes aglutinações pelos aloanticorpos anti-A, com títulos variando de 32 à 256. Cada amostra de plasma destes felinos apresentou um título diferente dos outros plasmas com anti-A. Portanto, uma amostra de plasma (25\%) apresentou aglutinação na diluição 1:32, outra amostra de plasma (25\%) apresentou aglutinação na diluição 1:64, outra amostra (25\%) na diluição $1: 128$ e outra (25\%) na diluição 1:256. Apesar de os títulos serem apenas obtidos na visualização microscópica, a grande quantidade de aloanticorpos anti-A nestes plasmas permite a visualização macroscópica das aglutinações em variados graus de diluições, como pode ser visualizada na microplaca na Figura 3, onde pode ser vista a não sedimentação de hemácias nas primeiras diluições da maioria dos plasmas, caracterizando a aglutinação nestes poços ${ }^{(4,16,20,33,34)}$. 


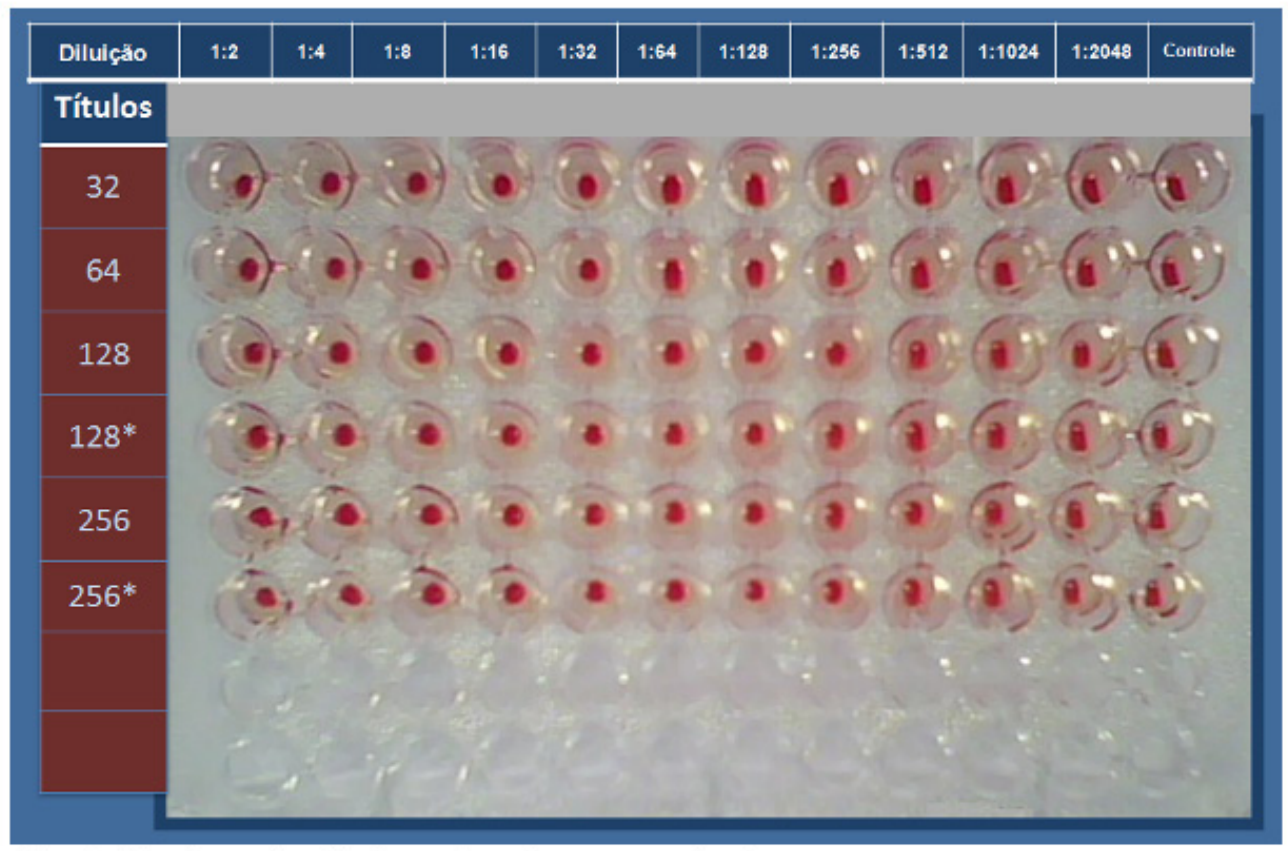

Obs.: * (Duplicata das diluições dos plasmas anteriores)

Figura 3: Titulação em diluições em PBS realizada em microplaca de 96 poços de todos os plasmas com aloanticorpos anti-A, todas as titulações conferidas em microscopia óptica. Nesta há visualização de aglutinações em variados graus de diluições. Os títulos para cada plasma se encontram na barra ao lado da foto.

No presente estudo, os títulos não variaram com a idade, não havendo aumento ou diminuição nestes títulos com o avançar da idade; não houve, portanto, variância nos títulos de aloanticorpos naturais totais nos felinos tipo A. Campbell e colaboradores ${ }^{(36)}$ relataram que os níveis de imunoglobulinas como IgM e IgA aumentam em animais idosos; no entanto, isso não tinha sido observado no gato. Elevados níveis de imunoglobulinas tem sido observados em idades avançadas em humanos e camudongos $^{(37-39)}$. Zhao e colaboradores ${ }^{(39)}$ relataram que o aumento dos níveis de imunoglobulinas com a idade possa ser devido ao aumento de células secretoras de anticorpos, assim como verificado por Cossarizza e colaboradores ${ }^{(40)}$, que relataram que o aumento de linfócitos B e plasmócitos em outros órgãos, ou aumento na produção por célula, aumentam os níveis de imunoglobulinas. No entanto, nenhum estudo relacionado aos títulos de aloanticorpos tem demonstrado que os efeitos da idade, doenças ou fatores ambientais modifiquem os títulos de aloanticorpos naturais ${ }^{(20,34,35)}$.

\section{Conclusões}

A obtenção da frequência dos grupos de sistema sanguíneo $\mathrm{AB}$ na população de felinos na cidade foi importante para estimar o risco de reação adversa através da transfusão sanguínea randomizada entre felinos não tipados previamente. A probabilidade de ocorrer a reação depende, portanto, da prevalência dos tipos sanguíneos no local, assim como o risco de ocorrência de isoeritrólise neonatal em filhotes pode ser um problema comum em felinos de raça pura na região, quando são realizados cruzamentos entre felinos que não possuem mesmo tipo sanguíneo.

Portanto, antes da primeira transfusão, os felinos devem ser tipados para a realização de transfusões compatíveis. No entanto, se a tipagem sanguínea não for possível de ser realizada em situações de urgência ou emergência, sugere-se realizar os testes de compatibilidade por prova cruzada no felino doador e receptor. Assim como a tipagem, os testes de compatibilidade são realizados para determinar se os sangues são compatíveis.

A presença de indivíduos com tipo sanguíneo B mostra a necessidade da tipagem de maior número de animais para que se tenha um cadastro destes na cidade, caso venham a necessitar de transfusão 
sanguínea ou na seleção de reprodutores, além de tornar a tipagem sanguínea parte da rotina clínica médica felina quando for necessária a transfusão sanguínea.

\section{Referências}

1. Knottenbelt $\mathrm{CM}$. The feline $\mathrm{AB}$ blood group system and its importance in transfusion medicine. Journal of Feline Medicine and Surgery. 2002;4:69-76.

2. Hohenhaus AE. Importance of blood groups and blood group antibodies in companion animals. Transfusion Medicine Reviews. 2004;18:117-126.

3. Weingart C, Giger B, Kohn B. Whole blood transfusions in 91 cats: a clinical evaluation. J. of Feline Medicine and Surgery. 2004;6:139-148.

4. Auer L, Bell K. The AB blood group system of cats. Anim Blood Groups Biochem Genet. 1981;12(4):287297.

5. Giger U. Blood typing and crossmatching to ensure compatible transfusions. Kirk's Curr. Vet. Ther. 2000;13:396-399.

6. Malik R, Griffin DL, White JD, Rozmanec M, Tisdall PL, Foster SF, Bell K, Nicholas FW. The prevalence of feline A/B blood types in the Sydney region. Aust Vet J. 2005;83(1-2):38-44.

7. Andrews GA, Chavey OS, Smith JE, Rich L. N-Glycolylneuraminic acid and N-acetylneuraminic acid define feline blood group A and B antigens. Blood. 1992;79:2485-2491.

8. Giger U, Bucheler J, Patterson DF. Frequency and Inheritance of A and B blood types in feline breeds of the United States. J Hered. 1991;82:15-20.

9. Arikan S, Duru SY, Gurkan M, Agaoglu ZT, Giger U. Blood Type A and B Frequencies in Turkish Van and Angora Cats in Turkey. J. Vet. Med. 2003;50:303-306.

10. Auer L, Bell K. AB blood group system in the domestic cat. Anim Blood Groups Biochem Gen. 1980,11:6364.

11. Haarer M, Grunbaum E. Blutgruppenserologische Untresuchunger bei katzen in Deutschland. Kleintierpraxis. 1993;38:195-204.

12. Jensen AL, Olesen AB, Arnbjerg J. Distribution of feline blood types detected in the Copenhagen area of Denmark. Acta Vet Scand. 1994;35:121-124.

13. Giger U. Blood type incompatibility in cats. Pandecats [internet]. 2002 Jun [citado em 26 deFev2010]. Disponívelem:http://www.pandecats.com/gen/author_index.php?name=Giger\&listname=Dr.\%20Urs\%20 Giger. Inglês.

14. Guerra TA, Lacerda LA, Oliveira ST, Esteves VS, Gonzalez FHD. Feline blood typing: 148 domestic cats in Lacvet - UFRGS laboratory routine. Acta Scientiae Veterinariae. 2007;35(2):573-574.

15. Medeiros AS, Soares AM, Alviano DS, Ejzemberg R, Silva MH. Frequencies of feline blood types in the Rio de Janeiro area of Brazil. Veterinary Clinical Pathology. 2008;37(3):272-276.

16. Arikan S, Akkan HA. Titres of naturally occurring alloantibodies against feline blood group antigens in Turkish Van cats. J. Small Animal Practice. 2004;45:289-292.

17. Knottenbelt CM, Addie DD, Day MJ, Mackin AJ. Determination of the prevalence of feline blood types in the UK. J Small Anim Pract. 1999a;40(3):115-118.

18. Arikan S, Gurkan M, Ozaytekin E, Dodurka, T, Giger, U. Frequencies of blood type A, B and AB in non- 
pedigree domestic cats in Turkey. Journal of Small Animal Practice. 2006;47:10-13.

19. Lacerda LA, Oliveira ST, Guerra TA, Stein GG, Gonzalez FHD. Prevalência dos tipos sanguíneos A, B e AB em gatos domésticos mestiços da cidade de Porto Alegre, Rio Grande do Sul, Brasil. Braz. J. vet. Res. anim. Sci. 2008;45: 46-53.

20. Knottenbelt CM, Day MJ, Cripps PJ, Mackin AJ. Measurement of titres of naturally occurring alloantibodies against feline blood group antigens in the UK. J. Small Animal Practice. 1999b;40:365-370.

21 Barfield D, Adamantos S. Feline blood transfusions: A pinker shade of pale. Journal of Feline Medicine and Surgery. 2011;13:11-23.

22. Kerl ME, Hohenhaus AE. Packed red blood cell transfusions in dogs: 131 cases (1989). J Am Vet Med Assoc. 1993;202:1495-1499.

23. Bagdi N, Magdus M, Leidinger E, Leidinger J, Voros K. Frequencies of feline blood types in Hungary. Acta Vet Hung. 2001;49(4):369-375.

24. Hubler M, Arnold S., Casal M, Fairburn A, Nussbaumer M, Rusch P. The blood group distribution in domestic cats in Switzerland. Schweiz Arch Tierheilkd. 1993;135(8):.231-235.

25. Ikemoto S, Sakurai Y. Individual difference within the cat blood group detected by isohemagglutinin. Nippon Juigaku Zasshi. 1981;43:433-435.

26. Jacomet L, Montoro A, Rivero MM, Giger U. Frequency of different blood groups in cats in Beunos Aires. Rev de Med Vet (Buenos Aires). 1997;78:428-431.

27. Leidinger J, Leidinger E, Giger U. Distribution and importance of feline blood type-A and type-B in Austria. Wien Tierarztl Monat. 1993;80:10-14.

28. Ruiz de Copegui R, Velasquez M, Espada Y. Survey of feline blood types in the Barcelona area of Spain. The Veterinary Record. 2004;154(25):794-795.

29. Continanza R, Lubas G, Gugliucci B. Indagini prelimisul di gruppo sanguigno AB nel gatto allevato in Italia. Atti Soci Ital Sci Vet. 1992;XLVI:1470-1477.

30. Silvestre-Ferreira AC, Pastor J, Almeida O, Montoya A. Frequencies of feline blood types in northern Portugal. Veterinary Clinical Pathology. 2004;33:204-243.

31. Von Haarer M, Grunbaum EG. Zur klinischen bendentung der blutgruppen bei katzen. Die Edelkatze. 1990;1:12-14.

32. Ejima H, Kurokawa K, Ikemoto S. Feline red blood cell groups detected by naturally occurring isoantibody. Japan J. Veterinary Science. 1986;48:971-976.

33. Giger U, Kilrain CG, Filippich LJ, Bell K. Frequencies of feline blood groups in the United States. J Am Vet Med Assoc. 1989;195(9):1230-1232.

34. Bucheler J, Giger U. Alloantibodies against A and B blood types in cats. Veterinary Immunology and Immunopathology. 1993;38:283-295.

35. Gurkan M, Arikan S, Ozaytekin E. Titres of alloantibodies against A and Blood types in non-pedeigree domestic cats in Turkey: assessing the transfusion reaction risk. J. Feline Medicine and Surgery. 2005;10:1-5.

36. Campbell DJ, Rawlings JM, Koelsch S, Wallace J, Strain JJ, Hannigan BM. Age-related differences in parameters of feline immune status. Veterinary Immunology and Immunopathology. 2004;100:73-80.

37. Bátory G, Jancsó A, Puskás E, Redei A, Lengyel É. Antibody and immunoglobulin levels in aged humans. Arch. Gerontol. Geriatr. 1984;3:175-188. 
38. De Greef GE, Van Tol MJ, Van den Berg JW. Serum immunoglobulin class and IgG subclass levels and the occurrence of homogeneous immunoglobulins during the course of ageing in humans. Mech. Age Dev. 1992;66:29-44.

39. Zhao KS, Wang YF, Gueret R, Weksler ME. Dysregulation of the humoral immune response in old mice. Int. Immunol. 1995,7:929-934.

40. Cossarizza A, Ortolani C, Monti D, Franceschi C. Cytometric analysis of immunosenescence. Journal Cytometry. 1997;27(4):297-313. 